\title{
Modeling the selection of the optimal stock portfolio based on the combined approach of clustered value at risk and Mental Accounting
} Seyedeh Farrokh Nikoo*

*Corresponding Author, Department of Financial Management, Qazvin Branch, Islamic Azad University, Qazvin, Iran. (Email: nikoo7_77@yahoo.com)

\section{Shahabeddin Shams}

Department of Financial Management, Qazvin Branch, Islamic Azad University, Qazvin, Iran. (Email: shahabeddinshams@gmail.com)

\section{Reza Tehrani}

Prof., Department of Finance, Faculty of Management, University of Tehran, Tehran, Iran. (Email: rtehrani@ut.ac.ir)

\section{Mohsen Seighali}

Prof., Department of Financial Management, Qazvin Branch, Islamic Azad University, Qazvin, Iran. (Email: seighali@ut.ac.ir)

Document Type: Original Article

Received: 2020/12/31

Accepted: 2021/04/05
2021, Vol. 5, No. 2. 70-94.

Published: 2021/04/21

\section{Abstract}

This paper concentrates on the modelling of optimal stock portfolio selection based on Risk Assessment and Behavioral Financial Approach Mental Accounting and 28 expert's opinion. In this approach developing the model approved by the opinion of academic and practical experts using quantitative and qualitative methods. Using quarterly return data of industrial indices for ten years in form of eight training and two test years indicates that the performance of DMSS and MVO based portfolios is equal however by regarding the value at risk and liquidity constraints in modeling, DMSS based portfolios perform higher than MVO portfolios.

Keywords: Portfolio Optimization, Mental Accounting, Value at Risk 


\section{Introduction}

Choosing the optimal portfolio is one of the most important topics in financial literacy and its purpose is to maximize future returns and minimize investment risk. Identifying the factors involved in investor decision-making and measuring these factors, as well as how they affect portfolio selection and control, are major problems for financial analysts. In a general approach, stock theories about portfolio construction can be divided into modern and postmodern groups. New (modern) portfolio management with the Markowitz average variance model was introduced in 1952 and by introducing a model based on risk and return and presenting an efficient frontier, for the first time, the risk category was placed next to the return as another variable to select the stock portfolio and the standard deviation was considered as a scattering index, a numerical risk criterion. In this theory, investors should choose an efficient portfolio from among the portfolio on the efficient border according to the contact level of their functionality with the efficient border. But in postmodern portfolio theory, based on the relationship between return and adverse risk, the investor behavior and the selection of the optimal stock portfolio are explained. Value at Risk (VaR) is the most well-known measure in the family of adverse risk measures, which provides more reasonable estimates of stock portfolio risk by eliminating the assumptions that are generally considered for risk assessment. This criterion lacks sum ability, meaning that the risk value of a portfolio may be greater than the total risk value of each asset alone (Chandra, 2008). On the other hand, according to various evidence that investors do not behave rationally and repeat mistakes in human evaluation and judgment, behavioral factors and psychological characteristics, including mental accounting, greatly influence people's decisions and these factors should be considered as risk factors when making decisions. While Markowitz's average variance portfolio theory has been silent about the ultimate goals of portfolio consumption, Schafer and Stedman's behavioral portfolio theory have proposed these goals. Investors in behavioral portfolio theory do not view their portfolio as a whole, but as a set of subset accounts, each subset of which is related to a goal \& each goal has a threshold level. In fact, investors consider the expected returns and the risk of each subset with the probability of failure to reach the return threshold level. Behavioral portfolio theory states that the efficient boundary is considered for each subjective account separately, and that risk is the probability of not reaching the return threshold level rather than the standard deviation of returns one of the basic tenets of financial behavior is the idea that investors are not risk-averse, but loss-making. In other words, people's hatred of uncertainty is not so great, but they hate to lose more than anything (Shefrin \& Statman, 2000). People are often sensitive to more harm 
than good, That is, the mental punishment that people incur for a certain level of loss is greater than the mental reward that they consider for the same level of profit. This phenomenon was first introduced in the perspective theory of Daniel Chainman and Amos Tversky\& it was based on the principle that people perceive loss as stronger than profit, and that people who are at a loss are even more willing to take risks to escape the loss-making situation. Frameworks \& mental arithmetic is part of vision theory that discusses the tendency of individuals to place special events in different mental arithmetic based on physical characteristics (Chang \&Young, 2018). The problem of portfolio selection and optimization can be seen as a combination of traditional behavioral financial and financial models and it is important to solve this model in such a way that the factors involved in decision making that affect the investor's choice can be taken into account. Therefore, a new model, which is a combination of Markowitz's theory and Schifrin and Stedman's theory, has been created in the framework of mental accounting and is called DMSS for short. This model is designed to help decision-makers to improve their decision making. In subjective accounting, the concept of risk is the probability of failure and reaching the threshold level in each of the subjective accounts. The DMSS model generally reduces the estimation risk compared to the Markowitz model. In this model, in addition to the desire to maximize returns and reduce risk, the maximum tolerable losses in each portfolio with different probabilities as well as changing thresholds are examined (Jiang, Ma \& Ann, 2013). Considering the importance of introducing new and behavioral approaches in the field of portfolio optimization and the lack of a suitable and relevant background in the country's capital market, the data deals with a behavioral finance approach and mental accounting. From this perspective, the present study can be considered in the field of behavioral finance and a new approach to portfolio optimization. As a result, it can be stated that the main task of this research is to design a model for portfolio optimization based on a behavioral finance approach focusing on subjective accounting and comparing the performance of selected portfolios based on the Markowitz method and Markowitz combined approach and subjective accounting with constraints extracted from Expert opinions on the practical function of portfolio optimization. The main purpose of this research in the qualitative section is to select appropriate criteria for portfolio selection and model the selection of the optimal stock portfolio based on risk assessment and behavioral financial approach (subjective accounting) in the Tehran Stock Exchange based on expert opinions. The sub-objective of the research, which is related to the quantitative part of the research, is the comparative evaluation of portfolio optimization methods with the development of risk calculation methods of 
variance at risk value and the introduction of mental accounting variables of investors in portfolio selection

\section{Research Background}

Markowitz's 1952 paper on portfolio selection suggests the average expected return and the variance of the return on the investment portfolio are generally assumed as the criteria for selecting the investment portfolio that securities beliefs or predictions follow the same probabilistic rules that random variables obey (Hoffmann \& Post, 2013). Most financial and economic theories are based on the concept that rational people behave and take all information into account in the decision-making process. On the other hand, researchers have found a lot of evidence that shows irrational behavior and repetition of errors in human evaluation \& judgment. Behavioral factors and psychological characteristics, including mental accounting, greatly affect people's decisionmaking and these factors should be considered as risk factors when making decisions (Islam, 2012). Mental accounting was first introduced by Richard Taller. He stated that mental accounting seeks to describe the process by which individuals codify, classify, and evaluate economic consequences. Mental accounting is inherently a practical and useful method that consumers use strategically to simplify cognitive calculations and automatically adjust costs (Chen, Wang \& Zhang, 2019) \& (Jamshidi \& Ghalibaf, 2019). Humans tend to keep certain events in their minds in the form of images, and these mental images will sometimes have more effects on our behavior and decisions than the events themselves. According to the concept of mental accounting, people in their financial decisions evaluate each decision, open a separate account in mind and try to examine the consequences of each decision (positive or negative) alone. Thaler's 1985 study showed that people not only evaluate decisions separately but also change the type of decision and the time spent spending and benefiting (Chen, Wang \& Zhang, 2019). Mental accounting states that people are mentally inclined to divide their assets into different portfolios and want to manage each portfolio independently. In other words, Exchanges are evaluated individually rather than continuously (Das, Markowitz, Scheid \& Statman 2010). Mental accounting implies that people tend to make decisions about different financial issues in separate mental accounts. Regardless of the logical assumption that it is better to make all of these decisions in one portfolio, mindful accounting practically ignores the interaction between different decisions. Some people, for example, do not seek to optimize their portfolio when investing but buy stocks separately without considering their relationship with each other (Das, Markowitz, Scheid \& 
Statman, 2010). Another practical concept in mental accounting is the concept of formatting, this concept means that each person's method mentally constitutes a transaction in his mind that will ultimately determine the desirability and expected desirability of the person. This concept is similarly used in Chainman and Trotsky's perspective theory many mental accounting theorists use the concept of formatting as a value function in their analysis (Baptista, 2012). It can be shown that people do not have consistency and consistency in making investment decisions. Of course, this is due to instability in people's moods, which leads to a change in their desirability. Of course, this is due to instability in people's moods, which leads to a change in their desirability. In other words, no fixed utility model for individuals can be imagined. The mental states, as well as the quality of the physiological state of individuals, have a profound effect on the desirability of their moment, which in turn leads to different decisions being made in different situations. An example of subjective accounting is that a person may borrow at a high-interest rate to buy a consumer good, while at the same time-saving in a low-interest rate account to support his or her child's education. According to Markowitz, these investors don't take into account the covariance between assets in their investment decisions, so their portfolio is below the working line (Piri, Salahi \& Mehrdoust, 2014).

The introduction of the theory of mental accounting and the existence of such a description of human behavior about money and wealth has distorted some of the basic assumptions of traditional economics. Creating mindful accounts in portfolio management is also debatable. In other words, investors deal with each component of their investment portfolio separately. This can lead to inefficient decision making. In fact, in portfolio rational theory, investors should focus on the ultimate desirability of their investment, not the components of the portfolio. However, investors tend to separate their wealth level into a safe account (to guarantee a certain level of wealth) and a risk account (to do risky transactions). The issue of mental accounting bias is not only relevant to individual investors but also institutional investors.

Fisher and Stedman (1997) point out in their research that mutual funds use the asset pyramid to create their portfolio. The pyramid consists of the first layer of cash at the bottom of the pyramid, then the bonds, and finally the stock at the top of the pyramid. Such behavior can be seen in the behavioral theory of portfolio presented by Schifrin and Stedman (2000). Their descriptive theory involved the creation of a multi-layer basket structure in which, of course, the covariance between layers is not considered and the basis for layer classification can have different criteria. One of the common criteria is a 
classification based on risk. So each layer is like a separate mental account. Mental accounting provides a framework for decision-makers to provide a set of reference points for each account and determine its profit and loss. Mental accounting implies that people tend to make decisions about different financial issues in separate mental accounts. Regardless of the logical assumption that it is better to make all of these decisions in one portfolio, mindful accounting practically ignores the interaction between different decisions. Another practical concept in mental accounting is the concept of formatting. This concept means that each person's method mentally constitutes a transaction in his mind that will ultimately determine the desirability and expected desirability of the person ( Shefrin \& Statman, 2000). Mental accounting can be discussed in three areas of research. The first area refers to how revenue is perceived and how post-implementation decisions are evaluated. The accounting system generates information for the cost-benefit analysis for both the past and the future. The second area refers to the allocation of activities to specific accounts. Both resources and expenditures of funds are labeled (such as the classification of accounts in conventional accounting). Capital expenditures are categorized into separate accounts, and expenditures are limited by designated budgets. The third area refers to the periodicity of the evaluation of accounts and the classification of choices. Accounts may be daily, weekly, or yearly ( Piri, Salahi \& Mehrdoust, 2014). While Markowitz's average variance portfolio theory has been silent about the ultimate goals of portfolio consumption, Shiffrin and Statman's Behavioral Portfolio Theory (DMSS) have proposed these goals. Investors in behavioral portfolio theory do not present their portfolio as a whole. Instead, investors see their portfolio as a collection of sub-accounts, each of which is linked to a purpose, and each goal has a threshold level \& an efficient boundary is set for each mental account and risk is the probability of not reaching the level of the return threshold instead of being the standard deviation of the returns. The DMSS model is a combination of Markowitz's theory and Shiffrin and Statman's theory developed in the framework of mental accounting. In subjective accounting, the concept of risk is the probability of failure and failure to reach the threshold level in any of the subjective accounts. The DMSS model generally reduces the estimated risk compared to the Markowitz model. In this model, in addition to the desire to maximize returns and reduce risk, the maximum tolerable losses in each portfolio with different probabilities as well as changing thresholds are examined (Das, Markowitz, Scheid \& Statman, 2010).

In modern portfolio theory, the risk is defined as the variability of total returns around the average and is calculated using the variance criterion. 
Assuming that the distribution is normal, the variance is an acceptable measure of return risk, but real-world research refutes this assumption. In fact, a rational investor with a short-term vision not only seeks positive stock price fluctuations but also welcomes them. These investors are looking for a way to measure the negative fluctuations of the portfolio under their management and, based on the results, select the optimal portfolio with the least adverse risk on average. The value at risk model is one of the key risk measurement indicators currently used by financial analysts in a variety of ways. This measure of risk in risk management is for legislative purposes, measuring the amount of risk, as well as a measure of the amount of capital an organization needs to perform its operations. Risk calculation in today's investment portfolio includes a variety of financial instruments, these include stocks, bonds, and a variety of derivative instruments that can only be measured through this VaR indicator, because there is no linear relationship between the return on assets and the underlying asset pledged in derivatives, other methods cannot be used to calculate risk. By definition, at-risk value is the maximum loss from which the decrease in the value of the portfolio for a given period in the future will not exceed a certain degree of confidence. In other words, VaR measures the worst expected loss under normal market conditions over a period of time and at a certain level of confidence (Jiang, Ma \& Ann, 2013). Value-at-Risk as one of the indicators of adverse risk is a measure of the maximum potential portfolio loss provided by Waterston. Value-at-Risk, Measures risk quantitatively and are one of the key and common tools in risk management discussion. By definition, at-risk value is the maximum loss from which the decrease in the value of the portfolio for a given period in the future will not exceed a certain degree of confidence. In other words, VaR measures the worst expected loss under normal market conditions over a period of time and at a certain level of confidence (Sina \& Fallah,2020) \& (Zare, Nilchi \& Fareed, 2020). In 2019, Chen et al. Introduced a new measure called MMVaR to examine high-density data and showed that this index has a better interpretation of the data and also calculates and reports a higher risk in the simulations and so it can become a more appropriate measure of daily risk calculation (Chen, Zhicheng \& Zhengjun, 2019).

The results of studies on the use of portfolio selection methods in Iran indicate that these models have been used in recent years in studies of Iranian researchers. Most of the present research has been on the use of algorithms such as neural networks, ant colony, genetic algorithm, bee colony, and other common algorithms in financial field studies to optimize and select the optimal portfolio. Examples include testing the risk-value model for forecasting and 
managing investment in the Tehran Stock Exchange by Iqbal Nia et al., Portfolio optimization using the risk-value model in the Tehran Stock Exchange by Karimi et al. A review of artificial intelligence-based stock price forecasting methods by Bayat \& Bagheri et al. However if the investor is riskaverse and seeks high returns, there is not much difference between the VaR and Markowitz methods. Also, studies in the field of behavioral finance and mental accounting have been conducted, but the study of mental accounting in selecting the optimal portfolio has not been done.

\section{Methodology}

This research is generally of a mixed research type. A hybrid approach is a type of research in which the researcher combines the elements and features of quantitative and qualitative approaches (eg, using point of view, data collection, analysis, and quantitative and qualitative inference techniques) for deeper and broader proof and understanding. Researching a mixed-method involves collecting, analyzing, and interpreting data qualitatively and quantitatively in a single study or in a set of studies that study a single phenomenon (Naderi \& SeifNaraghi, 2011). Model variables are qualitatively confirmed after reviewing the literature by referring to the opinions of experts and then the quantitative process of modeling and model testing is performed. In part, it is practical in terms of the type of goal and this emphasis is further because applied research is directed towards the practical application of knowledge. Also, to better understand the existing conditions and use the research results in decision making and selecting the most optimal portfolio, it is included in the descriptive and survey research group. In fact, research questions and hypotheses are presented in two parts, qualitative and quantitative. In the qualitative part, the research question is what are the effective factors in considering the elements of subjective accounting in portfolio optimization modeling? In a small part, the research question is this can better portfolios be achieved by developing the Markowitz portfolio optimization model using the Behavioral Financial and Mental Accounting (DMSS) approach?

In the qualitative part, the research has no hypothesis. But in the quantitative part, the research hypotheses are defined as follows:

- The first hypothesis: Portfolios from DMSS-based methods perform better than portfolios from MVO methods.

- $\quad$ The second hypothesis: VAR-modified DMSS portfolios perform better than VaR-modified MVO portfolios. 


\section{Research plan}

The outline of the research consists of five stages:

1.1.Select variables

a. A list of research variables required for portfolio optimization is extracted from the research literature. These variables include variance, value at risk, liquidity criteria, average simple portfolio return, etc.

b. The extracted variables in the previous step have been provided to the experts for refinement and selection.

c. Take the opinion of experts and apply the changes and suggestions provided.

d. Summarize the opinions of experts and obtain reconfirmation during the interview process until an agreement is reached on the variables and the sample under review based on the Delphi method.

1.2.Extracting the data

To conduct research, the data required for portfolio selection have been selected and extracted.

1.3.Extraction of optimal portfolios

a. The sample is divided into two training and testing sets.

b. Optimal portfolios have been extracted.

1.4.Performance evaluation of portfolios and models

a. Performance indicators of portfolio risk and return have been calculated and measured during the test period.

b. The performance of the extracted portfolios during the experimental period is compared.

c. The models were compared in two experimental and training periods.

\subsection{Conclusion}

Check the results of the hypothesis test.

\section{Population, sample and sampling method}

The population of this research consists of two parts. The first part is related to the selection of experts for a survey on the selection of variables studied in the research. In this section, experts who have sufficient experience in the field of academia, teaching \& research, as well as in the field of implementation and management of companies, portfolios \& investment funds, are considered the statistical community. In the second part of the statistical population, which is 
related to extracting the data required to form a portfolio, all companies listed on the Tehran Stock Exchange, whose symbol does not stop continuously for more than 45 working days during the period under review, are the population.

In the first part, which is related to the selection of experts, the snowball sampling method is used. The Snowball sampling method is non-probabilistic and is related to cases where the studied units are not easily identifiable. Especially when these units are very rare or make up a small part of a very large population. That this method, the statistician uses or assists in identifying and selecting the second sampling unit. In the same way, other units of the sample are identified and selected. Snowball sampling is used when there is no framework for sampling [12]. Finally, the opinions of 28 experts from the academic and operational fields and the fund manager, portfolios, and investment companies were used. In the second part of this study, all companies that are subject to the definition of the statistical community are examined, so typically, the sampling of this study is a time sampling that tries to generalize the results to periods other than the time under study.

\section{Data Collection tools}

Regarding data collection tools, notes will be used for library studies. The notes tool is one of the best tools for collecting data in the form of library studies. Notes maintain their credibility and reliability at a high level by mentioning the source (referring to the primary or secondary source). A data summary table has been used to study the documents. Sites and databases used include the site of Tehran Stock Exchange Technology Management Company, other official sites related to the capital market for collecting historical information required for research and software used including Excel to aggregate data and perform calculations related to risk and return \& XLSTAT software. To simulate distribution functions, finally, we used $\mathbf{R}$ software to perform calculations and portfolio formation and optimal portfolio selection.

\section{Data timeframe and research scope}

In terms of time domain, this research includes a ten-year period in which the required data related to various stock exchange industries are collected every week from the beginning of July 2008 to the end of June 2016. To study the models, first, the data from July 2008 to the end of June 2016 have been used. We call this data model training data. The rest of the data is then used to test the specified model. We call this data model test data. The spatial territory is all companies listed on the Tehran Stock Exchange. 


\section{Data analysis method and model fitting tool}

To select appropriate variables to investigate the investment portfolio risk and select the optimal portfolio, first by conducting a survey of experts in this field and examining the variables affecting the portfolio formation process and summarizing expert opinions, important variables and research indicators such as risk value, portfolio return, the criterion of liquidity and separation of the research period into two periods of testing and training were determined. In the optimization section, for performing calculations, the 10-year research period is divided into two parts, experiment and training, according to the experts. So that from the beginning of the study period up to $80 \%$ of the study period is selected as the training period and the remaining $20 \%$ until the end of the mentioned period is selected as the experimental period to measure the optimal portfolios selected in the training period in the experimental period. In the training course, based on the MVO method, the optimal portfolios are extracted, then by entering the VaR limit, the calculations are repeated \& new optimal portfolios are extracted. Optimal portfolios are then extracted based on the DMSS method, which is based on the Markowitz method in terms of subject accounting. New optimal portfolios are extracted. Finally, the results of each of the above three methods are compared with each other $\&$ in the experimental period, the mentioned methods are repeated \& the results of each method in the training and testing period are compared \& the hypotheses are tested to perform calculations, evaluation, and selection of optimal portfolios, first, the risk-value method is used to calculate the portfolio risk, then to select the optimal portfolios, the mean of variance will be updated, then the meanvariance method modified with $\mathrm{VaR}$, and finally the determination of optimal portfolios based on the MVO model modified with VaR and DMSS will be used in both experimental and training courses.

In general, constrained optimization problems can be shown as follows:

Minimize or Maximize: $\mathrm{F}(\mathrm{X})$

Subject to: $g_{i}(x) \leq 0 \quad \mathrm{I}=1,2,3, \mathrm{p}$

$$
\begin{array}{ll}
h_{j}(x)=0 & \mathrm{j}=1,2,3, \mathrm{q} \\
X_{k}^{\text {min }}<X_{k}<X_{k}^{\max } & \mathrm{k}=1,2,3, \mathrm{n}
\end{array}
$$

Where $X=\{$ is the design vector, and the above relations are unequal, equal constraints, and acceptable limits for design variables, respectively. The Markowitz model is based on the selection of the beam based on the highest efficiency, and at the same time, the lowest variance or equivalently 
maximizing the value of the difference in variance means maximizing the value of where $\mathrm{W}$ is the weight of the portfolio. To consider the amount of risk-taking or risk-aversion in determining the portfolio, based on the ratio of the second derivative to the first derivative of the utility function, the amount of gamma factor $(\gamma)$, which is called risk aversion factor, in the equation considered to be.

$$
\begin{aligned}
& \max \omega^{\prime} \mu^{\epsilon} \\
& \omega \in \mathrm{R}^{\mathrm{N}} \\
& \text { s.t. } \omega^{\prime} 1 \mathrm{~N}=1 \\
& \omega^{\prime} \sigma_{\mathrm{ij}} \omega=\min \sigma^{2}{ }_{\omega}
\end{aligned}
$$

$\boldsymbol{\omega}^{\prime} \boldsymbol{\sigma}_{i j} \boldsymbol{\omega}$ Matrix of variance and covariance, $\boldsymbol{\mu}^{\epsilon}$ Yield estimate symbol, W vector weight of assets in the portfolio. Value at risk as one of the indicators of adverse risk is a measure of the maximum possible loss of the portfolio, which is formulated as follows:

$$
\operatorname{VaR}=M \cdot Z_{\alpha} \cdot \sigma \sqrt{T} \mathrm{VaR}
$$

Value at Risk, $\alpha$ : confidence level, M: Asset market value, T: The length of the period calculates the returns $\& \sigma$ : Deviation is the criterion.

Therefore, we formulate the MVO model modified with VaR as follows:

$$
\begin{aligned}
& \max \omega^{\prime} \mu^{\epsilon} \\
& \omega \in \mathrm{R}^{\mathrm{N}} \\
& \text { s.t. } \omega^{\prime} 1 \mathrm{~N}=1 \\
& \omega^{\prime} \sigma_{\mathrm{ij}} \omega=\min {\sigma^{2}}_{\omega}^{\epsilon} \\
& \mathrm{P}^{\epsilon}\left[\operatorname{VAR}_{\omega}<\mathrm{H}_{\mathrm{m}}\right] \leq \beta_{\mathrm{m}}
\end{aligned}
$$

$\boldsymbol{\omega}^{\prime} \boldsymbol{\sigma}_{i j} \boldsymbol{\omega}$ Matrix of variance and covariance, $\boldsymbol{\mu}^{\boldsymbol{\epsilon}}$ Yield estimate symbol, $\mathbf{W}$ vector weight of assets in the portfolio, and VaR Value at Risk.

The MVO model modified with VaR and DMSS is formulated as follows: 


$$
\begin{aligned}
& \max \omega^{\prime} \mu^{\epsilon} \quad \omega \in \mathrm{R}^{\mathrm{N}} \\
& \text { s.t. } \omega^{\prime} 1 \mathrm{~N}=1 \\
& \omega^{\prime} \sigma_{\mathrm{ij}} \omega=\min \sigma_{\omega}^{2^{\epsilon}} \\
& \mathrm{P}^{\epsilon}\left[\mathrm{r}_{\omega}<\mathrm{H}_{\mathrm{m}}\right] \leq \alpha_{\mathrm{m}} \\
& \mathrm{P}^{\epsilon}\left[\mathrm{VAR}_{\omega \mathrm{n}}<\mathrm{H}_{\mathrm{m}}\right] \leq \beta
\end{aligned}
$$

$\boldsymbol{\omega}^{\prime} \boldsymbol{\sigma}_{i j} \boldsymbol{\omega}$ Matrix of variance and covariance, $\boldsymbol{\mu}^{\boldsymbol{\epsilon}}$ Yield estimate symbol, W vector weight of assets in the portfolio.

\section{Research Findings}

\section{Examine the process and the result of the qualitative part}

First, a model on the factors affecting portfolio selection based on the literature was extracted, which includes the following variables and provided to the experts.

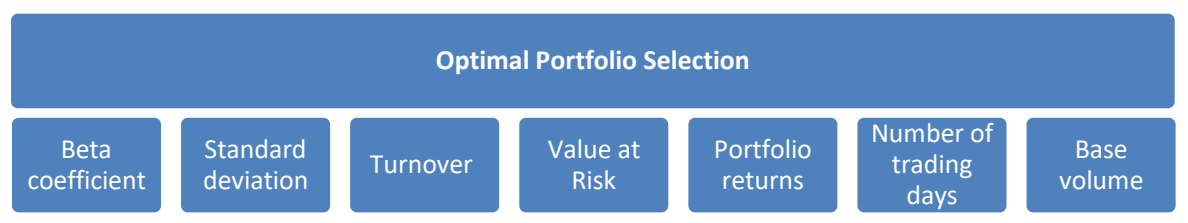

Figure 1. Graph of proposed variables

As mentioned before, the group of experts was selected as a snowball and

\begin{tabular}{|c|c|c|c|c|}
\hline \multirow{5}{*}{$\begin{array}{r}100 \% \\
50 \% \\
0 \%\end{array}$} & \multirow{2}{*}{$38 \%$} & $62 \%$ & $81 \%$ & \multirow[b]{2}{*}{$19 \%$} \\
\hline & & & & \\
\hline & & & & 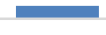 \\
\hline & 5 to 10 years & More than 10 years & P.H.D & Masters \\
\hline & \multicolumn{2}{|c|}{ Work Experience } & \multicolumn{2}{|c|}{ education } \\
\hline
\end{tabular}
the frequency distribution of their education and job records is as shown in the table below. The number of people is 28 , which due to the convergence of opinions and the adequacy of the results, as well as the relative coverage of the experts in question, interviews and finding new people have been stopped.

Figure 2. Status of work experience and education of experts 
The proposed model to the experts, after modifying and consolidating the experts' opinions, was selected to select the optimal portfolio in the form of the following diagram:

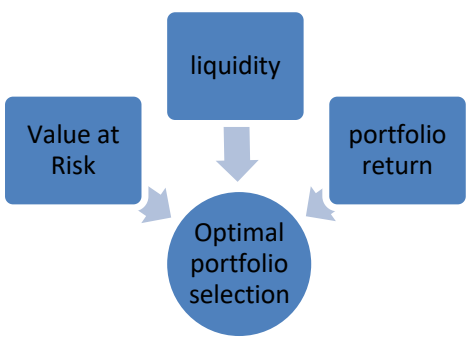

Figure 3. Selected Expert Variables (Research Findings)

To determine the appropriate criteria for portfolio selection, first, the criteria of beta indices, standard deviation, and risk value were selected as portfolio risk measures and using a simple portfolio return calculation method to determine the return on the investment portfolio. Due to restrictions such as base volume, fluctuation range, and other legal issues that do not allow trading in high volumes in the shares of all companies, to bring the research result closer to the real conditions of the Iranian capital market, Liquidity criterion based on the use of sales range, trading volume and number of trading days more than the base volume per share to 28 financial experts who work in the field of portfolio management in the Iranian capital market and also financial instructors in They for them are also universities, it was suggested. Then, according to the survey of experts and the aggregation of the opinions of all professors, and finally the agreement on the summary made by them, Companies whose price information is less than 4 years in the 10 years under review and as a result historical price simulation is not possible, It was removed from the statistical population and as a result, 18 industries active in the market, which constitute $92 \%$ of the total value of the Tehran Stock Exchange, were selected as the statistical population of the study. In order to reduce the effect of risks associated with each company, industry return data has been used. Then, the value-at-risk index was determined as a criterion for assessing portfolio risk, trading volume as a criterion for liquidity and using a simple portfolio return calculation method to determine the return on the investment portfolio. 


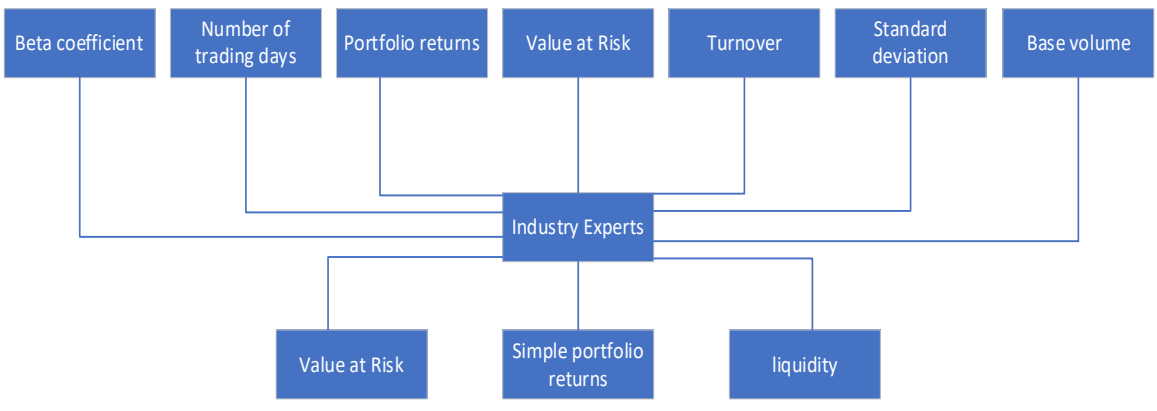

Figure4. Diagram of the process of selecting variables

\section{Examining the first hypothesis}

The first hypothesis states that portfolios from DMSS-based methods perform better than portfolios from MVO methods.

To test this hypothesis, first, the average historical return of all industries active in the Tehran Stock Exchange, whose price information and returns are available, is extracted for the 10-year period under study, which includes 18 industries. Then the research course is divided into two parts: experiment and training so that from the beginning of the study period up to $80 \%$ of the study period is selected as the training period \& the remaining $20 \%$ until the end of the mentioned period is selected as the experimental period to measure the optimal portfolios selected in the training period in the experimental period. In the training course, based on the DMSS method, which is based on the Markowitz method in terms of mental accounting, optimal portfolios are extracted. Then the optimal portfolios are extracted based on the MVO method $\&$ finally, the results of each of the two methods are compared in the period, and the first hypothesis is tested.

The Markowitz model is based on the choice of the beam based on the highest efficiency, \& at the same time, the lowest variance or equivalently maximizing the value of the difference in variance means maximizing the value Where $\mathrm{W}$ is the weight of the portfolio.

To consider the amount of risk-taking or risk-aversion in determining the portfolio, based on the ratio of the second derivative to the first derivative of the utility function, the amount of gamma factor $(\gamma)$, which is called risk aversion factor, in the equation considered to be. For the case where the gamma value is 1, it is interpreted as the normal Markowitz model (MVO).

First, a total of 18 selected industries are examined based on experimental data to determine the optimal portfolio. Based on the following equation and 
based on different gamma values, the optimal portfolio is selected. Then, for the experimental data, the mean value and variance of the total portfolio are calculated. Accordingly, the portfolio with the highest returns is the risk-averse portfolio, which consequently has the highest variance (risk). In determining the optimal portfolio weights by considering the risk aversion criterion, the results are presented in the table below. Using the weights obtained from the selected portfolio on the training data, the average value and variance of the portfolio are calculated for the test data. According to the results for training data, a high-risk portfolio with an elevation of $0.81 \%$ has the highest return. The position of the portfolios and the efficient frontier \& the Violet chart in the training course are presented in the following chart:
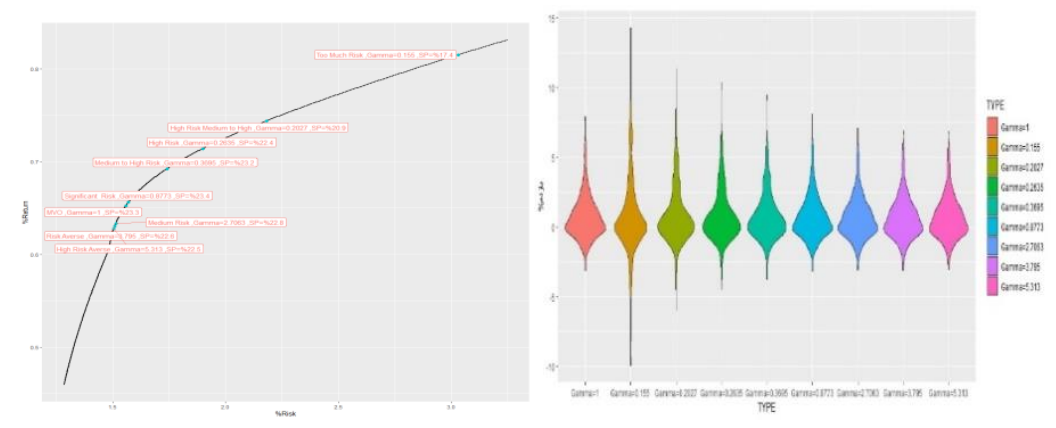

Figure 5.Efficient and violet boundary for training data and position of selected portfolios for different gamma values (research findings)

After extracting the optimal portfolio using 8-year data, it is necessary to measure and compare the performance of these portfolios during the two-year same period. According to the training data, the weight of the selected portfolio has been calculated. Then, for the test data, the portfolio return and its risk are calculated, which is shown in the diagram below.
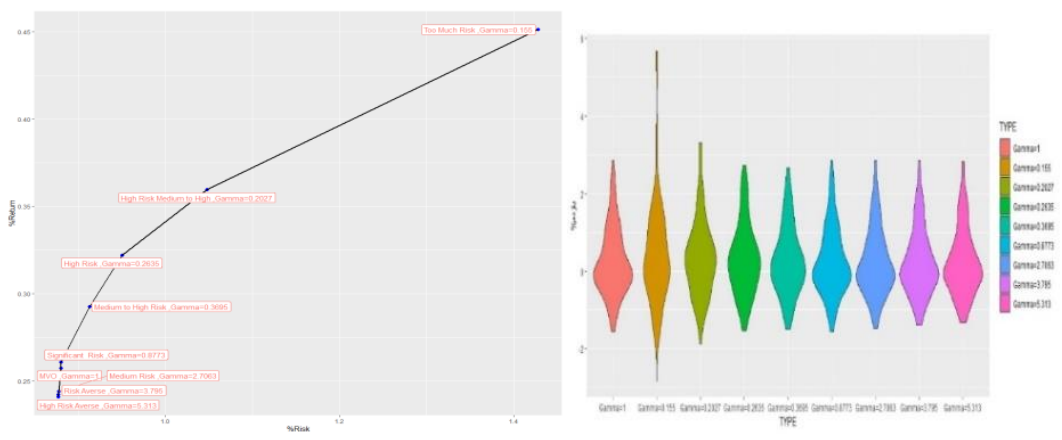

Figure 6. Return and Violet Risk for Experimental Data for Different Gamma Values (Research Findings) 
To evaluate the performance of portfolios, the Sharp ratio was obtained for each series of portfolios, and to significantly measure the performance difference at different levels of risk, the Sharp ratio parity test between the series was performed and the results are presented in the table below.

Table 1. Sharp parity test to compare portfolio performance (research findings)

\begin{tabular}{|c|c|c|c|c|c|c|}
\hline $\begin{array}{c}\text { Significance } \\
\text { level }\end{array}$ & $\begin{array}{l}\text { Degrees of } \\
\text { freedom }\end{array}$ & $\begin{array}{c}\text { Test } \\
\text { statistics }\end{array}$ & SR2 & SR1 & $\begin{array}{c}\text { second } \\
\text { distribution }\end{array}$ & First distribution \\
\hline 0.6424 & 103 & -0.466 & 0.321 & 0.284 & Gamma $=0.155$ & Gamma $=1$ \\
\hline 0.2331 & 103 & -1.199 & 0.349 & 0.284 & Gamma $=0.2027$ & Gamma=1 \\
\hline 0.1906 & 103 & -1.317 & 0.337 & 0.284 & Gamma $=0.2635$ & Gamma $=1$ \\
\hline 0.1812 & 103 & -1.346 & 0.32 & 0.284 & Gamma $=0.3695$ & Gamma $=1$ \\
\hline 0.3821 & 103 & -0.878 & 0.286 & 0.284 & Gamma $=0.8773$ & Gamma $=1$ \\
\hline 0.2422 & 103 & 1.176 & 0.269 & 0.284 & Gamma $=2.7063$ & Gamma $=1$ \\
\hline 0.4691 & 103 & 0.727 & 0.272 & 0.284 & Gamma $=3.795$ & Gamma $=1$ \\
\hline 0.524 & 103 & 0.639 & 0.271 & 0.284 & Gamma $=5.313$ & Gamma $=1$ \\
\hline 0.4035 & 103 & -0.839 & 0.349 & 0.321 & Gamma $=0.2027$ & Gamma $=0.155$ \\
\hline 0.7406 & 103 & -0.332 & 0.337 & 0.321 & Gamma $=0.2635$ & Gamma $=0.155$ \\
\hline 0.9821 & 103 & 0.023 & 0.32 & 0.321 & Gamma $=0.3695$ & Gamma $=0.155$ \\
\hline 0.6557 & 103 & 0.447 & 0.286 & 0.321 & Gamma $=0.8773$ & Gamma $=0.155$ \\
\hline 0.5525 & 103 & 0.596 & 0.269 & 0.321 & Gamma $=2.7063$ & Gamma $=0.155$ \\
\hline 0.5827 & 103 & 0.551 & 0.272 & 0.321 & Gamma $=3.795$ & Gamma $=0.155$ \\
\hline 0.5813 & 103 & 0.553 & 0.271 & 0.321 & Gamma $=5.313$ & Gamma $=0.155$ \\
\hline 0.4779 & 103 & 0.712 & 0.337 & 0.349 & Gamma $=0.2635$ & Gamma $=0.2027$ \\
\hline 0.3441 & 103 & 0.951 & 0.32 & 0.349 & Gamma $=0.3695$ & Gamma $=0.2027$ \\
\hline 0.2318 & 103 & 1.203 & 0.286 & 0.349 & Gamma $=0.8773$ & Gamma $=0.2027$ \\
\hline 0.2139 & 103 & 1.251 & 0.269 & 0.349 & Gamma $=2.7063$ & Gamma $=0.2027$ \\
\hline 0.2466 & 103 & 1.165 & 0.272 & 0.349 & Gamma $=3.795$ & Gamma $=0.2027$ \\
\hline 0.2525 & 103 & 1.151 & 0.271 & 0.349 & Gamma $=5.313$ & Gamma $=0.2027$ \\
\hline 0.2446 & 103 & 1.17 & 0.32 & 0.337 & Gamma $=0.3695$ & Gamma $=0.2635$ \\
\hline 0.1853 & 103 & 1.334 & 0.286 & 0.337 & Gamma $=0.8773$ & Gamma $=0.2635$ \\
\hline 0.1841 & 103 & 1.337 & 0.269 & 0.337 & Gamma $=2.7063$ & Gamma $=0.2635$ \\
\hline 0.2254 & 103 & 1.22 & 0.272 & 0.337 & Gamma $=3.795$ & Gamma $=0.2635$ \\
\hline 0.2361 & 103 & 1.192 & 0.271 & 0.337 & Gamma=5.313 & Gamma $=0.2635$ \\
\hline 0.1705 & 103 & 1.38 & 0.286 & 0.32 & Gamma $=0.8773$ & Gamma $=0.3695$ \\
\hline 0.1832 & 103 & 1.34 & 0.269 & 0.32 & Gamma $=2.7063$ & Gamma $=0.3695$ \\
\hline 0.2434 & 103 & 1.173 & 0.272 & 0.32 & Gamma $=3.795$ & Gamma $=0.3695$ \\
\hline 0.2621 & 103 & 1.128 & 0.271 & 0.32 & Gamma $=5.313$ & Gamma $=0.3695$ \\
\hline 0.2566 & 103 & 1.141 & 0.269 & 0.286 & Gamma $=2.7063$ & Gamma $=0.8773$ \\
\hline 0.4498 & 103 & 0.759 & 0.272 & 0.286 & Gamma $=3.795$ & Gamma $=0.8773$ \\
\hline 0.4983 & 103 & 0.679 & 0.271 & 0.286 & Gamma $=5.313$ & Gamma $=0.8773$ \\
\hline 0.5028 & 103 & -0.672 & 0.272 & 0.269 & Gamma $=3.795$ & Gamma $=2.7063$ \\
\hline 0.7769 & 103 & -0.284 & 0.271 & 0.269 & Gamma $=5.313$ & Gamma $=2.7063$ \\
\hline 0.8884 & 103 & 0.141 & 0.271 & 0.272 & Gamma $=5.313$ & Gamma $=3.795$ \\
\hline
\end{tabular}


Since the significance level of the tests is higher than $5 \%$, the parity of the Sharp ratio for these distributions is not rejected. Therefore, it can be stated at a 95\% confidence level that there is no significant difference between the performance of DSMM and MVO portfolios.

Since the liquidity index was expressed by experts as one of the main indicators and it was necessary to consider it in the modeling and evaluation process of the model, the index was designed and adjustments were made in the optimization model. In this regard, the average volume of sales of industries in the past three months is considered \& by dividing it by the volume of the portfolio, an index was designed to explain the relative liquidity. Also, a constraint was added to the model to observe twenty working days for portfolio liquidity. The designed model is presented below.

$$
\begin{gathered}
\text { Mean_Var }=\operatorname{Max}_{W_{i}}\left\{W^{T} \mu-\frac{1}{2} \gamma W^{T} \Sigma W\right\} \\
W^{T} e=1.0 \leq W_{i} \leq T_{i} . i=1 . \ldots .18
\end{gathered}
$$

In determining the optimal portfolio weights by considering the risk criterion, using the weights obtained from the selected portfolio on the training data, the average value and variance of the portfolio are calculated for the test data.
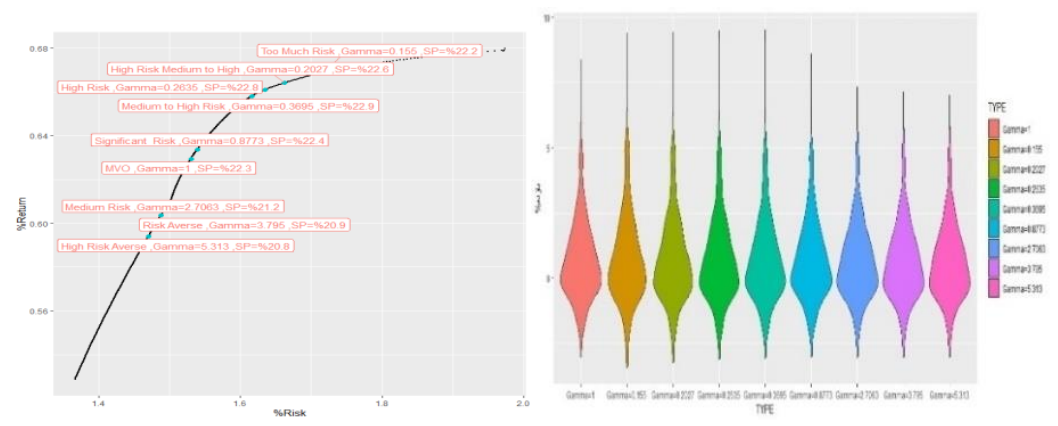

Figure7. Efficient boundary and Violet diagram for training data and position of selected portfolios (research findings)

After extracting the optimal portfolio using 8-year data, it is necessary to measure and compare the performance of these portfolios during the two-year same period. According to the training data, the weight of the selected portfolio has been calculated. Then, for the test data, the portfolio return and risk are calculated, which is shown in the diagram below. 


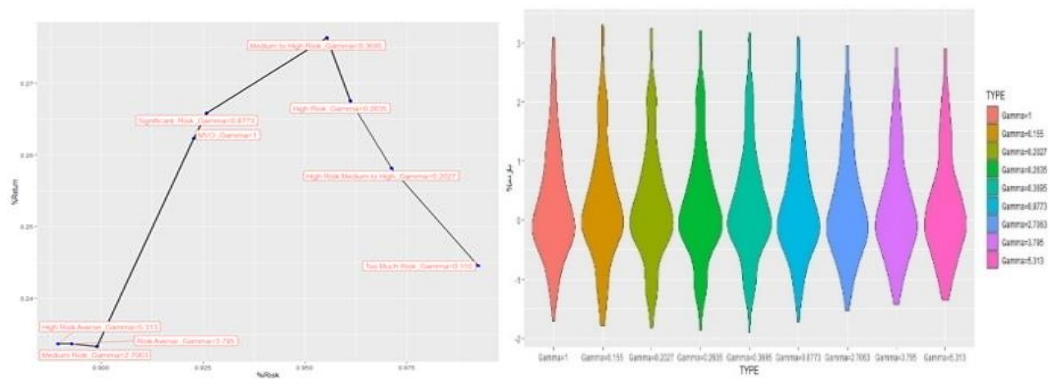

Figure 8. Efficient boundary and Violet diagram for test data and position of selected portfolios (research findings)

Again, to evaluate the performance of portfolios, the Sharp ratio for each series of portfolios was obtained, \& to significantly measure the performance difference at different levels of risk, the Sharp ratio parity test between the series was performed and the results are presented in the table below.

Table 2. Sharp Ratio Equality Test to Compare Portfolio Performance (Research Findings)

\begin{tabular}{|c|c|c|c|c|c|c|}
\hline $\begin{array}{c}\text { Significance } \\
\text { level }\end{array}$ & $\begin{array}{c}\text { Degrees } \\
\text { of } \\
\text { freedom }\end{array}$ & $\begin{array}{c}\text { Test } \\
\text { statistics }\end{array}$ & SR2 & SR1 & $\begin{array}{c}\text { second } \\
\text { distribution }\end{array}$ & First distribution \\
\hline 0.2413 & 103 & 1.178 & 0.252 & 0.289 & Gamma $=0.155$ & Gamma=1 \\
\hline 0.4481 & 103 & 0.761 & 0.271 & 0.289 & Gamma $=0.2027$ & Gamma $=1$ \\
\hline 0.7578 & 103 & 0.309 & 0.283 & 0.289 & Gamma $=0.2635$ & Gamma $=1$ \\
\hline 0.7493 & 103 & -0.32 & 0.294 & 0.289 & Gamma $=0.3695$ & Gamma $=1$ \\
\hline 0.1808 & 103 & -1.348 & 0.292 & 0.289 & Gamma $=0.8773$ & Gamma $=1$ \\
\hline 0.0592 & 103 & 1.908 & 0.262 & 0.289 & Gamma $=2.7063$ & Gamma $=1$ \\
\hline 0.1488 & 103 & 1.455 & 0.263 & 0.289 & Gamma $=3.795$ & Gamma $=1$ \\
\hline 0.221 & 103 & 1.231 & 0.264 & 0.289 & Gamma $=5.313$ & Gamma $=1$ \\
\hline 0.0288 & 103 & -2.217 & 0.271 & 0.252 & Gamma $=0.2027$ & Gamma $=0.155$ \\
\hline 0.0355 & 103 & -2.13 & 0.283 & 0.252 & Gamma $=0.2635$ & Gamma $=0.155$ \\
\hline 0.0431 & 103 & -2.048 & 0.294 & 0.252 & Gamma $=0.3695$ & Gamma $=0.155$ \\
\hline 0.193 & 103 & -1.31 & 0.292 & 0.252 & Gamma $=0.8773$ & Gamma $=0.155$ \\
\hline 0.7837 & 103 & -0.275 & 0.262 & 0.252 & Gamma $=2.7063$ & Gamma $=0.155$ \\
\hline 0.7755 & 103 & -0.286 & 0.263 & 0.252 & Gamma $=3.795$ & Gamma $=0.155$ \\
\hline 0.7777 & 103 & -0.283 & 0.264 & 0.252 & Gamma $=5.313$ & Gamma $=0.155$ \\
\hline 0.0476 & 103 & -2.005 & 0.283 & 0.271 & Gamma $=0.2635$ & Gamma $=0.2027$ \\
\hline 0.0576 & 103 & -1.92 & 0.294 & 0.271 & Gamma $=0.3695$ & Gamma $=0.2027$ \\
\hline 0.3561 & 103 & -0.927 & 0.292 & 0.271 & Gamma $=0.8773$ & Gamma $=0.2027$ \\
\hline 0.7986 & 103 & 0.256 & 0.262 & 0.271 & Gamma $=2.7063$ & Gamma $=0.2027$ \\
\hline 0.833 & 103 & 0.211 & 0.263 & 0.271 & Gamma $=3.795$ & Gamma $=0.2027$ \\
\hline 0.8489 & 103 & 0.191 & 0.264 & 0.271 & Gamma $=5.313$ & Gamma $=0.2027$ \\
\hline 0.0707 & 103 & -1.826 & 0.294 & 0.283 & Gamma $=0.3695$ & Gamma $=0.2635$ \\
\hline 0.6192 & 103 & -0.498 & 0.292 & 0.283 & Gamma $=0.8773$ & Gamma $=0.2635$ \\
\hline & & & & & & \\
\hline
\end{tabular}




\begin{tabular}{|c|c|c|c|c|c|c|}
\hline 0.4731 & 103 & 0.72 & 0.262 & 0.283 & Gamma $=2.7063$ & Gamma $=0.2635$ \\
\hline 0.5308 & 103 & 0.629 & 0.263 & 0.283 & Gamma $=3.795$ & Gamma $=0.2635$ \\
\hline 0.5644 & 103 & 0.578 & 0.264 & 0.283 & Gamma $=5.313$ & Gamma $=0.2635$ \\
\hline 0.8881 & 103 & 0.141 & 0.292 & 0.294 & Gamma $=0.8773$ & Gamma $=0.3695$ \\
\hline 0.2331 & 103 & 1.199 & 0.262 & 0.294 & Gamma $=2.7063$ & Gamma $=0.3695$ \\
\hline 0.2987 & 103 & 1.045 & 0.263 & 0.294 & Gamma $=3.795$ & Gamma $=0.3695$ \\
\hline 0.342 & 103 & 0.955 & 0.264 & 0.294 & Gamma $=5.313$ & Gamma $=0.3695$ \\
\hline 0.0637 & 103 & 1.875 & 0.262 & 0.292 & Gamma $=2.7063$ & Gamma $=0.8773$ \\
\hline 0.1422 & 103 & 1.479 & 0.263 & 0.292 & Gamma $=3.795$ & Gamma $=0.8773$ \\
\hline 0.2054 & 103 & 1.274 & 0.264 & 0.292 & Gamma $=5.313$ & Gamma $=0.8773$ \\
\hline 0.8485 & 103 & -0.192 & 0.263 & 0.262 & Gamma $=3.795$ & Gamma $=2.7063$ \\
\hline 0.8789 & 103 & -0.153 & 0.264 & 0.262 & Gamma $=5.313$ & Gamma $=2.7063$ \\
\hline 0.9226 & 103 & -0.097 & 0.264 & 0.263 & Gamma $=5.313$ & Gamma $=3.795$ \\
\hline
\end{tabular}

As can be seen, the significance level of the tests is higher than $5 \%$ \& in their case, the parity of the Sharp ratio for these distributions has not been rejected. Therefore, in the case of these portfolios, it can be stated with $95 \%$ confidence that there is no significant difference between the performance of DSMM and MVO portfolios, even taking into account the liquidity limit.

\section{Examining the second hypothesis}

The second hypothesis states that VAR-modified DMSS portfolios perform better than VaR-modified MVO portfolios.

To test this hypothesis, as in the first hypothesis, first, the average historical return of all industries operating on the Tehran Stock Exchange, whose price information and returns are available, is extracted for the 10-year period under study, which includes 18 industries. Then the research course is divided into two parts: experiment and training. So that from the beginning of the study period up to $80 \%$ of the study period is selected as the training period $\&$ the remaining $20 \%$ until the end of the mentioned period is selected as the experimental period to measure the optimal portfolios selected in the training period in the experimental period. In the training course, based on the DMSS method, which is based on the Markowitz method in terms of mental accounting, optimal portfolios are extracted. Then, the optimal portfolios based on the MVO method are calculated by entering the VaR constraint and new optimal portfolios are extracted. Finally, the results of each of the above two methods are compared $\&$ in the experimental period, the mentioned methods are repeated $\&$ the results of each method. In the training and testing period, it is compared \& the second hypothesis is tested.

In the $\mathrm{VaR}$ model, the risk criterion of portfolio selection is defined as $W^{T} \mu-z_{\alpha} \sqrt{W^{T} \sum W}$ Where the value of $z_{-} \alpha$ is equal to the standard normal 
distribution quotient for the alpha value. First, by solving the following equation for all 18 industries, the selected portfolio is determined.

$$
\begin{gathered}
V a R=\operatorname{Max}_{W_{i}}\left\{W^{T} \mu-z_{\alpha} \sqrt{W^{T} \Sigma W}\right\} \\
W^{T} e=1.0 \leq W_{i} \leq 1
\end{gathered}
$$

As in the previous paragraph, the criterion of liquidity is considered \& the optimal portfolio is selected based on the Ti constraint on the beam weights. In fact, the following equations are optimized.

$$
\begin{aligned}
& \operatorname{VaR}_{\text {Gamma }}=\operatorname{Max}_{W_{i}}\left\{W^{T} \mu-\gamma V a R\right\} \\
& \operatorname{Max}_{W_{i}}\left\{W^{T} \mu-\gamma\left\{W^{T} \mu-z_{\alpha} \sqrt{W^{T} \Sigma W}\right\}\right\} \\
& W^{T} e=1,0 \leq W_{i} \leq T_{i} . i=1 . \ldots .18
\end{aligned}
$$

According to the training data, the weight of the selected portfolio has been calculated. Portfolio returns and risk are then calculated for the test data. This test is clustered in the form of three alpha values for the VaR-related constraint. In fact, the test is performed in the following form:

Table 3. Results of analysis of variance (research findings)

\begin{tabular}{|c|c|}
\hline Category & Gamma \\
\hline Very risk-averse & $\mathbf{0 . 1 5}$ \\
\hline Risk aversion & $\mathbf{0 . 8 7}$ \\
\hline MVO & $\mathbf{1}$ \\
\hline Risk-taking & $\mathbf{2 . 7 1}$ \\
\hline Very risky & $\mathbf{5 . 3 9}$ \\
\hline
\end{tabular}

Table 4. (Research Findings)

\begin{tabular}{|c|c|c|c|}
\hline DMSS & MVO & $\begin{array}{c}\text { Model Modification } \\
\text { Basis (VaR Alpha) }\end{array}$ & Category \\
\hline $\begin{array}{c}\text { Very risk-averse, risk-averse, risk-averse, } \\
\text { highly risk-averse }\end{array}$ & Gamma=1 & 0.9 & Cluster1 \\
\hline $\begin{array}{c}\text { Very risk-averse, risk-averse, risk-averse, } \\
\text { highly risk-averse }\end{array}$ & Gamma=1 & 0.95 & Cluster2 \\
\hline $\begin{array}{c}\text { Very risk-averse, risk-averse, risk-averse, } \\
\text { highly risk-averse }\end{array}$ & Gamma=1 & 0.99 & Cluster3 \\
\hline
\end{tabular}

It is now necessary to compare the Sharp index in each of the four portfolios with the DMSS portfolios. For this purpose, one-factor analysis of variance test was used. The results of the analysis of the variance test are as follows: 
Table 5. Results of analysis of variance (research findings)

\begin{tabular}{|c|c|c|c|}
\hline The significance level & Degrees of freedom & Test statistics & Category \\
\hline$\cdot / \cdots$ & 12 & $12 / 73$ & Cluster1 \\
\hline$\cdot \cdots$ & 12 & 11.46 & Cluster2 \\
\hline$\cdot \cdots$ & 12 & $13 / 22$ & Cluster3 \\
\hline
\end{tabular}

Since the significance level is less than $5 \%$, the parity of Sharp performance ratios is rejected. The Tukey auxiliary test provides the following ranking.

Table 6. Ranking Results by Tukey Auxiliary Test (Research Findings)

\begin{tabular}{|c|c|c|c|c|c|c|}
\hline \multirow{2}{*}{$\begin{array}{c}\text { Optimization } \\
\text { model }\end{array}$} & \multicolumn{2}{|c|}{ Cluster1 } & \multicolumn{2}{c|}{ Cluster2 } & \multicolumn{2}{c|}{ Cluster3 } \\
\hline \multirow{2}{*}{ first group } & $\begin{array}{c}\text { Very } \\
\text { risky }\end{array}$ & 0.44 & $\begin{array}{c}\text { Very } \\
\text { risky }\end{array}$ & 0.43 & Very risky & 0.38 \\
\cline { 2 - 7 } & $\begin{array}{c}\text { Risk- } \\
\text { taking }\end{array}$ & 0.41 & $\begin{array}{c}\text { Risk- } \\
\text { taking }\end{array}$ & 0.41 & Risk-taking & 0.37 \\
\cline { 2 - 7 } The second group & $\begin{array}{c}\text { Risk- } \\
\text { taking }\end{array}$ & 0.324 & $\begin{array}{c}\text { Risk- } \\
\text { taking }\end{array}$ & 0.39 & Very risky & 0.27 \\
\cline { 2 - 7 } & $\begin{array}{c}\text { Very } \\
\text { risky }\end{array}$ & 0.31 & $\begin{array}{c}\text { Risk- } \\
\text { taking }\end{array}$ & 0.31 & MVO & 0.26 \\
\hline \multirow{2}{*}{ The third group } & MVO & 0.289 & $\begin{array}{c}\text { Very } \\
\text { risky }\end{array}$ & 0.30 & & 0.33 \\
\cline { 2 - 7 } & & MVO & 0.28 & & 0.00 \\
\hline \multirow{2}{*}{ The significance } \\
level
\end{tabular}

Since in all cases, the MVO portfolio is in the low group \& in all cases, the significance level is less than $5 \%$, so at the $95 \%$ confidence level it can be said that DMSS-based portfolios perform better. For best results, the performance of all DMSS-based portfolios was averaged and grouped, and compared with MVO in a paired t-test:

Table 7. Student's t-test results (research findings)

\begin{tabular}{|c|c|c|c|c|}
\hline The significance level & Degrees of freedom & Test statistics & MVO & DMSS \\
\hline 0.00 & 102 & 4.33 & 0.272 & $\mathbf{0 . 3 6 8}$ \\
\hline
\end{tabular}

Since the significance level is less than $5 \%$, the hypothesis of equality of means is not confirmed \& at the $95 \%$ confidence level, it can be said that the DMSS performs better than the MVO. 


\section{Conclusion and Suggestions}

The main purpose of this study was to achieve a portfolio optimization model with a mental accounting approach and based on risk and return evaluation indicators based on experts. In this regard, first, according to the literature and the aggregation of experts, the variables related to the optimal model are designed and then the model is tested on a plant in a 10-year period. For this purpose, portfolios were first formed based on mathematical models designed based on traditional optimization methods and subject accounting based on optimization (DMSS) and the optimization process has been done for them for an eight-year period (training period) and this process has led to the extraction of the weights of the optimal portfolios. Portfolios are then designed based on these weights and maintained for two years (experimental period). Finally, portfolio performance is measured and compared based on the Sharp ratio Modeling is developed by adding terms and restrictions related to $\mathrm{VaR}$ and liquidity, and the above process is repeated. The results of testing hypotheses show a higher efficiency of models based on subjective accounting in terms of considering VaR constraints and liquidity. Also, the results of both approaches are the same in simple conditions and without considering the operational and functional limitations as a result of testing the first hypothesis. These results are consistent with the results of similar research conducted by Cheng and Yang (2018), Jiang (2013), Hoffman (2010), Markowitz and Statman (2010), Hoffman (2013), and Batista (2012). However, the inclusion of some constraints has led to studies such as Amirkhani (2010) and Ginio (2005) not achieving equal results for the two models in the form without liquidity constraints and VaR. Meanwhile, Zare et al. (2020) have shown that the method based on stock price forecasting using technical indicators, as well as the Markowitz method only in the risk aversion portfolio does not offer better performance than the average market index. This is related to the findings of three different portfolios in the first part of the second hypothesis. Of course, it should be noted that the present study has optimized the portfolio based on Markowitz's theory, and according to the degree of risk acceptance and the effects of subjective accounting. Also, this research is retrospective and the rate of return of industries in the last eight years has been the basis for portfolio selection. Due to the prevailing macroeconomic variables and factors affecting the profitability of companies, as well as a significant increase in new companies entering the capital market and the lack of trading history of these companies, in the model used in the present study, companies with less trading history are not used. Therefore, in order to use the research results optimally and closer to reality, it is suggested. To select a portfolio, the performance 
status of industries and companies in the past should not be the basis of research, and the predictions of experts and fundamentalists of the trend of companies operating in the market should be used as the basis for portfolio selection for all companies, especially newcomers. It is also suggested that considering the use of financial leverage in most of the portfolios formed in the Tehran Stock Exchange, it is suggested that the basis for the percentage of use and the amount of risk incurred in the portfolio and also the selection of the optimal portfolio in terms of financial leverage be researched and evaluated.

Funding: This research received no external funding.

\section{References}

Baptista, A. M. (2012). Portfolio selection with mental accounts and background risk. Journal of Banking \& Finance, 36(4), 968-980.

Chandra, A. (2008). Decision-Making in the Stock Market: Incorporating Psychology with Finance. National Conference on forecasting Financial Markets of India, Available at SSRN: http://ssrn.com/abstract=1501721.

Chen, Yu \& Wang, Zhicheng\& Zhang, Zhengjun, 2019. "Mark to market value at risk," Journal of Econometrics, Elsevier, vol. 208(1), 299-321.

Das, S., Markowitz, H., Scheid, J., \&Statman, M. (2010). Portfolio optimization with mental accounts. Journal of Financial and Quantitative Analysis, 45(2), 311-334.

Gordon, j. Alexander, Alexandre M. Baptista, Shu Yan.2016. Portfolio Selection with Mental Accounts \& Estimation Risk.

Hoffmann, A. O. I., \& Post, T. (2013). What Makes Investors Optimistic, What Makes Them Afraid? Journal of Economic Literature.

Islam, S. (2012). Behavioral finance of an inefficient market. Global Journal of Management and Business Research, 12(14).

Jamshidi, N., \&Ghalibaf ASL, H. (2019). Dynamics of the Behavior of Individual Investors in Tehran Stock Exchange. Journal of Financial Management Perspective, (25), 101-120. (In Persian)

Jiang, C., Ma, Y., \& Ann, Y. (2013). International portfolio selection with exchange rate risk: A behavioural portfolio theory perspective. Journal of Banking \& Finance, 37(2), 648-659.

K.-H.Chang., M .N. Young. (2018). Portfolio Optimization Utilizing the Framework of Behavioral Portfolio Theory. International Journal of Operations 
Research Vol. 15, No. 1, 1-13

KhaliliAraghi, M., \&Yekkezare, A. (2010). Estimating of Market Risk of Industries of Tehran Stock Exchange based on VaR. Journal of Financial Review, (7), 47-72. (In Persian)

Naderi, E., \&SeifNaraghi, M. (2011). Research Methods and Its Evaluation in Human science. BadrPublishing. 20 Edition. (In Persian).

Piri, F. \& Salahi, M. \&Mehrdoust, F. (2014), Robust Mean- Conditional Value at Risk Portfolio Optimization, International Journal of Economic Sciences, Vol.III, No.1, 2-11

Sanjiv Das, Harry Markowitz, Jonathan Scheid, Meir Statman.2010. Portfolio Optimization with Mental Accounts. Journal of Financial \& Quantitative Analysis.

Sina, A., \&Fallah, M. (2020). Comparison of Value Risk Models and CoppolaCVaR in Portfolio Optimization in Tehran Stock Exchange.

Journal of Financial Management Perspective, (29), 125-146. (In Persian)

Shefrin, H. and M. Statman, (2000), "Behavioral Portfolio Theory", Journal of Financial and Quantitative Analysis, Vol. 35, Pp: 127-151

Zare, M.H., \&Nilchi, M., \& Fareed, D. (2020). Comparative Evaluation of Markowitz Approach with a New Hybrid Method to Create an Optimal Portfolio Using Deep DNN Learning Method and Gravitational Search Algorithm. Journal of Financial Management Perspective, (28), 165-188. (In Persian)

\section{Bibliographic information of this paper for citing:}

Nikoo, Seyedeh Farrokh; Shams, Shahabeddin; Tehrani, Reza \& Seighali, Mohsen (2021). Modeling the selection of the optimal stock portfolio based on the combined approach of clustered value at risk and Mental Accounting. Iranian Journal of Finance, 5(2), 70-94.

Copyright ( 2 2021, Seyedeh Farrokh Nikoo, Shahabeddin Shams, Reza Tehrani and Mohsen Seighali 